\title{
PRASASTI KEDÊNGAN
}

\section{Oleh : M.M. Sokarto K. Atmodjo}

Baru-baru ini Bapak Letkol (Purn) Dihar Ronggoprawiro dari Mojoroto (Kêdiri) memperlihatkan sebuah lempengan tembaga bertulis kepada Universitas Kadiri (P.R. Il dr. Hartono Moedjisunu) dan selanjutnya faksimil (turunan tangan) prasasti tersebut dikirim oleh Bapak Koesdisarwojo kepada Lembaga Javanologi (Yayasan Panunggalan) di Yogyakarta untuk diteliti lebih lanjut. Prasasti tembaga itu berukuran ':. panjang $45,5 \mathrm{~cm}$, lebar $12,5 \mathrm{~cm}$ dan tebal sekitar $2,5 \mathrm{~mm}$. Menurut berita tembaga bertulis (ťmmraprasāsti) itu semula disimpan oleh seorang penduduk Bojonegoro di dalam sebuah peti bersama-sama sebilah keris dan sehelai kain cinde. Namun demikian asal atau tempat semula prasasti diketemukan (didapat) tidak diketahui secara jelas.

Sayang sekali tembaga bertulis itu tidak bernomor. Meskipun demikian dapat diperkirakan bahwa lempengan tembaga itu merupakan lembar ke-3 atau ke-4 dari prasasti selenggkapriya yang diduga terdiri atas 5, 6 atau 7 lempengan. Karena prasasti tidak lengkap, maka nama raja ataupun angka tahunnya tidak dapat diketahui secara pasti. Tetapi melihat bentuk (tipe) tulisan (dari segi paleografi), rupa-rupanya prasasti itu diturun (tinulad) pada jaman Majapahit berdasarkan prasasti aslinya yang lebih tua. Isi pokok prasasti menyebut anugerah|Paduka Sri Maharaja (namanya tidak diketahui) kepad desa Kêdêngan yang diangkat status atau kedudukannya menjadi sebuah sima (desa perdikan). Karena prasasti menyebut nama desa Kêdêngan, baiklah tembaga bertulis itu dinamakan prasasti Kêdêngan.

\section{TRANSLITERASI.}

Prasasti Kêdêngan ditulis dengan huruf (akșara) dan bahasa Jawa Kuna pada kedua belah sisinya (recto dan verso). Setiap sisi digores dengan empat baris kalimat. Huruf sangat jelas dan rupa-rupanya ditulis oleh seorang citralekha (penulis, pelukis) yang pandai. Bunyi kalimat atau langgam bahasanya agak mirip dengan prasasti Biluluk (1366 M.)1 dan prasasti Rênêk (1379 M.).2 Untuk memudahkan para pembaca yang belum biasa membaca prasasti maka huruf (suara) nasal ng tetap ditulis ng. Transliterasi selengkapnya sebagai berikut : 
Recto (sisi depan).

1. mangkana. ludan. tutan. angsaprtyangsa. daṇda kudaṇda. mañdihalādi. tan kataman byut-i.

2. kêdêngan. atạ pramäna i rika. nyang salwirning watêk kilalan. manadahi. tarimba. matapukan.

3. maban̂ol. salahan. wargga ri dalm. asing maka wargga ya. asing desa sasangkanya a-

4. sing saprawrttinya. yāwat humunggu i rikang sīma ring kêdêngan. pramāna byut-i kêdêngan sasu-

Verso (sisi belakang).

1. ka duḥkhanya kabeh. muwah-anugraha pāduka srí mahārāja i kê. dêngan. wnang-amangana rāja.

2. mangśa. lwirnya, wdus gt nting. hasu tugêl. karung pulih. badawang. wnang ahuluna pujut. wnatig-ahuluna.

3. bondan. wnang-ahuluna dayang. wnang-ahuluna cabol. wungkuk. wnang-anjamaha rare kawula.

4. wnang-atujula. wnang katêmwaning strí larangan. wnang-adŗwya dagang sakweḥning-asambyawahāra, anga.

\section{TERJEMAKAN.}

Terlebih dahulu harus diketahui bahwa menterjemahkan prasasti merupakan pekerjaan yang sangat sulit. Hal ini disebabkan karena prasasti biasanya menggunakan kalimat yang singat dan padat (kort en bondig). Selain itu masih banyak kata-kata teknis (technical terms) dan ungkapan kalimat yang belum diketahui artinya secara jelas. Dengan demikian terjemahan di bawah ini hanyalah bersifat sementara dan sewaktu-waktu dapat berubah sesuai dengan perkembangan ilmu pengetahuan. Terjemahannya lebih kurang sebagai berikut :

Recto (sisi depan).

1. demikianlah, ludan tutan (sejenis denda, hukuman ?), angsaprtyangśa (yang berkaitan dengan keturunan, wakaf, cekcok antara keluarga atau ummat ?), denda mendenda (pukul-memukul), mencerca (maṇdihalādi) tidak mendapat tekanan (sanksi, buyut, beban) di 
2. Kêdêngan. Harap waspada (mengetahui) hal itu. Demikian pula semua golongan kilalan (orang asing, petugas tertentu), 3 pemukul genderang (manadahi), tarlmba (kelompok orang tertentu ?), pemain topeng (matapukan).

3. pelawak (mabañol), salahan (kelompok orang tertentu ?), 4 warga di dalam (cf. nyêron beteng), dan sembarang (siapa saja) warga, dari mana pun juga asalnya (desanya).

4. dan bagaimana pun pula perangainya (asing saprawrtinya). apabila bertempat tinggal di desa perdikan Kêdêngan, supaya mengetahui segala peraturan (sanksi, beban, buyut) desa Kêdêngan tersebut.

Verso (sisi belakang).

1. segala macam (sukha-duhkha -nya (delict hukum, peraturan hukum dengan segala akibatnya). Dan lagi anugerah Päduka Srî Mahārāja kepada penduduk Kêdêngan.5 yaitu (mereka) diperbolehkan makan

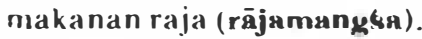

2. seperti : kambing (wdus gunting), anjing (hasu tugêl). n celeng (karung pulih), kura-kura (badawang), diperbulchkan inempunyai haniba (hulun : hudak) orang pujut, 7 boleh mempunyai hamba.

3. Orang bondan, 8 boleh mempunyai hamba dayang-(layang (dayang),9 boleh mempunyai hamba orang cebol (cabol), l() bungkuk (wungkuk). holeh menjamah (menangkap. mempunyai) anak hamba (rakyat).

4. bolch melakukan tujul (?).11 boleh menemui wanita larangan (strĩ larangan), 12 boleh berdagang segala macam dagangan. ...

\section{KETERANGAN SINGKAT.}

Seperti telah diterangkan di atas, prasasti tembaga itu menyebut nama sebuah desa Kêdêngan. Dikatakan bahwa desa Kêdêngan diangkat kedudukannya menjadi sebuah sima (desa perdikan) oleh Pãduka Srí Mahärāja. Sayang sekali anugerah menjadi sima itu tidak diketahui alasannya (sambandha), karena prasasti tidak lengkap. Demikian pula letak desa Kêdêngan belum diketahui secara pasti, karena nama-naına desa yang terletak di sekitarnya (wanua tplsiring) tidak diketahui (mungkin disebut dalam lempengan lainnya). Demikian pula apabila sekarang terdapat nama sebuah desa yang sama atau mirip ucapannya dengan Kèdêngan di daerah Jawa Timur (misalnya : Kanḍangan, Kêndêngan, Kệungan), hal itu juga belum menjamin, bahwa nama desa itu sama dengan Kêdengan di 
dalam prasasti. Hal ini disebabkan karena banyak nama-nama desa (toponim) di pulau Jawa yang sama ucapannya, seperti nama Lasêm (kota Lasêm di Jawa Tengah dan desa Lasêm dekat Grêsik),13 Walambangan (menjadi Lamongan dan daerah Blambangan), 14 Sêdayu (Sêdayu Lawas daerah Kab. Lamongan dan Sêdayu Kota daerah Kab. Grêsik). Demikian pula nama desa Mędowo terdapat di dua tempat, yaitu di dekat kota Mojokerto dan di dekat Pare (Kediri). Nama Mêdowo tersebut (salah satu di antaranya) mungkin dapat dikembalikan kepada nama Mădhawapura di dalam prasasti. Seperti telah diketahui di dalam prasasti yang diterbitkan oleh Dr. F.H. van Naerssen di dalam thesisnya Oudjavaansche Oorkonden in Duitsche en Deensche Veramelingen (hlm. 68 - 70) juga disebut nama bangunan suci (sang hyang dharmma) di Mādhawapura dan Krșnapura. Mãdhawa adalah nama lain dewa Wiṣnu (juga Madhusūdana) sedangkan Kẹ̣!a adalah penjelmaan (inkarnasi) ke- 8 dewa Wiṣnu (Krṣnāwatara). Di desa Mêdowo dekat Mojokerto itulah masih hanyak terdapat sisa-sisa pondasi bangunan kuna dari bahan batu hata (terracotta). Jadi suatu situs purbakala yang sangat penting dan perlu digali, lebih-lebih untuk membuktikan apakah desa Medowo sekarang ini sama dengan negara Mãdhawa (Mādhawapura) di dalam prasasti. Sebah apabila benar demikian. maka desa Mêdowo itulah merupakan sisa sebuah pura (bangunan suci, negara kecil) yang khusus memuja atau menghormati dewa Mãdhawa (Wiṣnu). Jadi ternıasuk kelompok atau sekte Waiṣnawa. Hal ini mudah diketahui karena dewa Wiṣnu adalah seorang dewa yang berlugas melindungi ummat manusia. Demikian pula gelar atau nama lengkap Sang Mapanji Jayabhaya dari Kaḍiri juga menyebut Madhusudanawātārānindita, artinya : sebagai penjelmaan dewa Wiṣnu yang tiada tercela (anindita). Denikian pula nama desa Mêdowo di dekat Pare (Kêdiri) perlu diteliti lebih lanjut, karena di daerah Pare masih terdapat nama desa Bẽsowo yang dapat diperkirakan sama dengan Bespawa (lokasinya dapat bergeser) di dalam prasasti Paraḑah II (10 Juli 943 M.). Sebelum menyebut Besṇawa batu Parađ̧ah II juga menyebut nama desa Kudur, dan desa Kudur (Kampung Baru) sekarang masih terletak tidak jauh dari kali Srinjing. Perlu dijelaskan di sini bahwa di desa Kudur itulah diketemukan prasasti Harinjing (Harin̂jing A, B dan C) yang dijadikan dasar pertimbangan untuk menentukan harijadi Kadiri, yaitu tanggal 25 Maret804 M.15 Demikian pula nama-nama desa sekarang di daerah Kêdiri (atau di sekitar Pare) seperti : Kanḍangan, Bogor Pradah, Adanadan, Prambatan, Kêdiri, Kuwak, Pagu, Cêkềr dapat dikembalikan kepada nama-nama desa kuna di dalam prasasti, yaitu : Kaṇḍang (sima kaṇdang), Paraḍah, Hadahada, Parambattan, Kaḍiri, Kwak (sang dewata lumah 1 kwak), 16 Bagu, Cêkèr. 17 
Selain kedudukan (status ) sima yang diberikan kepada desa Kêdêngan, penduduk desa (kurang jelas sebagian atau seluruhnya), juga mendapat anugerah dari Pāduka Śi Mahārāja, berupa :

1. Mereka diperboleh makan räjamangáa yang terdiri atas daging kambing (wdus guntlng), anjing (hasu tugêl). celeng (karung pullh) dan kurakura (badawang).

2. Diperbolehkan mempunyai hamba (hulun) orang pujut, bondon, dayang, orang cebol dan bungkuk.

3. Diperbolehkan menjamah anak hamba (rakyat?).

4. Diperbolehkan melakukan tujul (?).

5. Diperbolehkan menemui wanita larangan (stri larangan).

6. Diperbolehkan berdagang segala macam barang dagangan (wnangadrwya dagang sakwehning-asamby awahāra).

Di antara anugerah tersebut yang menarik perhatian ialah masalah räjamanysa (royal meat) yang terdiri atas beberapa macam daging binatang dan daging kura-kura. 18 Tentu saja selain ràjamangsa pada jaman dahulu juga terdapat berbagai macam daging binatang yang memang merupakan kegemaran rakyat. Di dalam kitab Nāgarakrtāgama (Pupuh 90, 2) misalnya dikatakan bahwa masyarakat sanga menyukai daging kodok (mandhuka, wiyung), cacing (krimi), kura-kura (kara), tikus (mūșika) dan juga daging anjing (şrgăla). Dikatakan bahwa masyarakat banyak yang menyukainya (kweh sakterika) dan mereka sangat senang memakannya (tusta). Tetapi didalam kita Nitisastra yang digubah pada jaman Majapahit akhir (sekitar tahun 1500 M.) dikatakan juga bahwa orang baik-baik (sang sujana) jangan memakan jenis daging yang tergolong jelek (kasta-mangsa), misalnya : daging tikus (muslka), anjing (sregala), kodok (wlyung), ular (ula), ulat (krlmi)19 dan cacing (kawat, katat). Jenis makanan tersebut di dalam kitab Nitisastra (Pupuh II, 12) disebut jenis makanan yang rendah (papahara)20 dan harus dijauhi. Maka jelaslah sekarng apabila di dalam prasasti Kedengan dan juga prasasti lainnya daging anjing (hasu tugel) tergolong makanan raja (rajamangsa), tetapi di dalam kitab Nitisastra di katagorikan makanan yang rendah (papahara). Demikian pula di dalam 
kitab Nagarakrtagama daging anjing hanya tergolong makanan rakyat jelata dan merupakan daging terlarang (hilahlla) serta rendah mutunya (alpa dahat).

Selain itu masalah budak atau hamba (hulun) di dalam prasasti Kêdêngan juga menarik perhatian. Dikatakan bahwa mereka diperbolehkan mempunyai hamba orang cebol (cabol) dan bungkuk (wungkuk). Karena keduanya mempunyai cacad tubuh, maka sudah jelas bahwa yang penting bukannya diperlukan tenaganya, melainkan manfaatnya yang bersifat gaib. Di kalangan masyarakat orang-orang cacad tersebut dianggap banyak mempunyai kekuatan mana (magische kracht). Jadi dapat dibanding dengan abdi cebolan atau abdi palawljan di kraton Yogyakarta.

Kecuali orang cebol dan bungkuk juga dikatakan bahwa mereka diperbolehkan mempunyai hamba orang pujut dan bondan. Apa yang dimaksud dengan kedua kelompok orang tersebut kurang jelas. Tetapi karena dikatakan bahwa orang pujut dan bondan boleh dijadikan budak (hulun), maka keduanya rupa-rupanya termasuk golongan yang'rendah kedudukannya. Boleh jadi mereka lahir dari perkawinan antara golongan (kasta) yang berlainan dan hidup berpindah-pindah. Maslah bondan ini bertambah menarik karena di dalam bahasa Jawa terdapat ungkapan kata berbunyi mbondan tanpa ratu yang diterjemahkan oleh Th. Piegeaud menjadi : wetteloos (zijn gang gaan)21 Selain itu di dalam masyarakat Jawa juga terkenal seubah tarian disebut tari bondan yang menggambarkan seorang ibu sedang menimang-nimang anaknya.

Selanjutnya di dalam kitab Babad Tanah Jawi (edisi W.L. Olthof) juga terdapat seorang tokoh bernama Raden Bondan Kêjawan. Diceritakan bahwa Bondan Kêjawan yang juga bernama Lểmbu Pêtêng lahir dari perkawinan antara Prabu Brawijaya yang berpenyakit kelamin (rajasinga) dengan putri Wanḍan yang berkulit kuning. Dikatakan bahwa penyakit kelamin raja Brawijaya itu akan sembuh apabila dapat berhubungan (tidur bersama) dengan putri Wandan. Supaya lebih jelas baiklah saya kutipkan cerita singkat di dalam kita Babad Tanah Jawi itu sebagai berikut : "Kacariyos prabu Brawijaya miyos sitinggil, ndangu datêng para nujum, punapa sasedanipun wontên ingkang nggêntosi kaprabonipun, ndarbeni panguwasa kados panjênênganipun. Aturipun para nujum, inggih wontên, 
tệakipun sang nata ugi. Nanging baḍe ngalih kadaton ing Mataram, ngedêpaken tiyang ing tanah Jawi sêdaya. Prabu Brawijaya mbotên mawi ngandika lajêng kondur ngadaton. Kala semanten sang nata gêrah rajasinga, lami mbotên sagêd miyos-miyos. Sawarnining jejampi mbotên mantunaken. Anuntên wanci dalu sang nata mireng swara : "Eh, sang nata, yen sira arep waras, atunggala turu wong Wanḍan kang kuning rupane." Sawungunipun sang nata lajêng munựut abdi estri Wanḍan, bêbêktanipun ingkang garwa saking nêgari ing Cêmpa. Sarêng dipun sareni sêpisan, sang nata saras gerahipun. Abdi estri wau wawrat, mbabar miyos kakung, abagus warninipun. Karsanipun sang nata, jabang-bayi kaparingakên ḍatêng abdi juru-sabin, anama kyai buyut Masahar. Nanging bilih sampun umur sawindu andikakakên mêjahi, awit pambatangipun para nujum, jabang-bayi punika ing benjing bade dados ratu, ngrisak panjênênganipun sang prabu. Nangin pambatangipun para nujum wau klintu.

Jabang-bayi kabêkta mantuk datêng ki Masahar, kapasrahakên ḍatêng semahipun, supados kapulasaraa. Sarêng sampun puput, dipun jềjuluki radenlBondan Kêjawan. Dumugi umur sêwindu, kyai buyut nyêrềpakên dạtêng semahipun, ingkang dados karsanipun sang nata wau. Lajêng ngunus curiga, bade mêjahi ing raden Bonḍan Kêjawan. Nyai buyut kêlếngêr, Kyahi Masahar sande nggenipun bade mejahi, enggal nulungi semahipun. Saking awrat ing trêsnanipun datêng ingkang estri, raden Bond̦an Kêjawan mboten siyos pêjah. Kyai Masahar lajểng sowan ing sang nata, awad, yen sampun nglampahi dawahipun. Sang nata sakêlangkung suka ing galih". 22

Di dalam Babad Tanah Jawi selanjutnya dikatakan bahwa Raden Bonḑan Kêjawan kemudian kawin dengan dewi Nawangsih dan berputra Ki Gêtas Pênḍawa, dan Gêtas Pênḍawa berputra Ki Agêng Sela yang selanjutnya menurunkan (Jawa : nurunakên). raja-raja Mataram II (Islam). Tokoh Ki Ageng Sela itu dapat dibanding dengan tokoh Dapunta Selendra yang merupakan cakal-bakal (wambakara) dinasti Sailendra dan menurunkan sebagian raja-raja Mataram I (Hindu).

Meskipun di dalam Babad Tanah Jawi dikatakan bahwa Raden Bondan Kêjawan seorang pemuda yang tampan (abagus waminipun) dan juga sakti (dapat membunuh dua orang begal dengan keris Malela), tetapi karena ayahnya berpenyakit kelamin (meskipun sembuh setelah sekali berkumpul dengan putri Wanḍan), tentunya Raden Bonḍan Kêjawan juga 
seorang pemuda yang kurang sehat (normal), entah jasmani maupun rohaninya. Mengapa pengarang Babad Tanah Jawi menghubungkannya dengan raja Brawijaya yang berpenyakit kelamin, belum diketahui secara jelas. Tetapi pasti ada sesuatu yang tersembunyi di dalamnya, lebihlebih mengingat bahwa Bondan Kểjawan juga dinamakan Lêmbu Pêtêng oleh Ki Agêng Tarub.

Selain tokoh Raden Bonḍan Kềjawan di dalam silsilah kraton juga terdapat tokoh Ki Bondan Surati. Dikatakan bahwa Ki Bonḑan Surati adalah putra Prabu Brawijaya V. Bondan Surati setelah meninggalkan kraton Majapahit kemudian mengembara ke daerah pegunungan selatan di daerah Jawa Timur dan Jawa Tengah. Kemudian Ki Bondan Surati berputra Ki Agêng Wanabaya, dan Ki Agêng Wanabaya berputra Ki Cakrawêsi. Selanjutnya menurunkan tokoh-tokoh tertentu di dalam masyarakat Jawa. Menurut cerita Ki Bondan Surati kemudian mati obong di daerah Gunung Kidul.

Demikianlah tokoh cerita babad yang menggunakan unsur nama bondan dan juga ungkapan kata mbondan tanpa ratu di kalangan masyarakat. Pertanyaan adakah hubungannya dengan bondan di dalam prasasti (misalnya prasasti Kêdêngan) belum dapat dijawab secara pasti. Yang jelas golongan orang bondan pada jaman dahulu boleh dijadikan budak atau hulun. Tetapi tokoh Bondan Kêjawan dan Bonḍan Surati kemudian dianggap menurunkan raja-raja atau tokoh penting di dalam masyarakat Jawa. Mungkin dengan temuan-temuan baru di kemudian hari masalah bondan, pujut dan strỉ larangan dapat dipecahkan secara memuaskan.

Akhirulkata perlu dijelaskan di sini bahwa sumber prasasti merupakan salah satu sumber sejarah yang sangat penting, karena dari sumber prasasti dapat diketahui berbagai macam masalah, seperti : pertanian, perdagangan (perekonomian), sistim perpajakan, birokrasi, tokoh-tokoh sejarah, agama, pembuatan tanggul, upacara, pembagian masyarakat, dan lain-lainnya.

Mudah-mudahan dalam waktu yang tidak lama lembar lainnya prasasti Kêdêngan dapat diketemukan kembali dengan segera, sehingga masalah yang penting sehubungan dengan sejarah kuna dapat diketahui lebih jelas lagi.

Sekian dan terimakasih.

\section{Soli Deo gloria.}




\section{Catatan.}

1. Lihat Th. Pigeaud : Java in the Fourteenth Century, Vol. I. hlm. 115.

2. W.F. Stutterheim dan Th. Pigeaud : Een belangrijke Oorkonde uit den Bloetijd van Mądjapahit, Djawa, 1926, hlm. 195 - 204.

3. Yang dimaksud dengan wārgga kilalān, antara lain : orang Kling, Āryya, Singhala, Pandikira, Drawida, Campa, Kmir, Rêmên, juga atapukant (topeng), abanol (pelawak), salaran (?). Lihat OJO. LVIII, prasasti Cane.

4. Di dalam prasasti Cane disebut salaran. Perubahan $r$ menjadi h misalnya nama tempat di Bali, Sakar sekarang menjadi Sakah. Kadangkadang $r$ malahan dihilangkan, seperti nama Gurang dan Darusa sekarang menjadi Guang (dekat Sukawati, Kab. Gianyar) dan Dausa (sebelah utara Kintamani, Kab. Bangli). Bentuk salaran lebih tua apabila dibanding dengan salahan.

5. Kurang jelas apakah kepada sebagian kecil penduduk (para pimpinan desa) ataukah kepada seluruh penduduk Kêdêngan.

6. Istilah gunting (untuk wdus) dan tugel (untuk hasu) belum jelas meskipun artinya diketahui. Apakah yang terpotong ekornya, telinganya, atau warna anjing dua macam?

7. Di pulau Lombok terdapat sebuah bukit keramat untuk orang Islam Waktu Têlu (sebelum 1965) yang disebut gunung Pujut. Di atas bukit itu terdapat sebuah masjid Islam Waktu Têlu dan juga sisa-sisa kebudayaan megalith. Sewaktu penulis mendaki gunung Pujut sekitar tahun 1967 bangunan masjid tidak lagi digunakan oleh masyarakat karena larangan dari pemerintah setempat.

8. Apakah kelompok masyarakat pengembara yang tidak terikat pada peraturan tertentu ? Ataukah bondan bérkaitan dengan Wandan, mengingat tokoh Bonḑan Kêjawan di dalam babad anak Brawijaya dengan putri Wandan, dan pujut berasal dari Lombok?

9. Rupa-rupanya dayang seorang hamba perempuan. Cf.dayang-dayang. 
10. Cf. abdl dalêm cebolan (palaw(lan) di kraton Yogyakarta.

11. Arti perkataan tujul kurang jelas. Akar kata Jul berhubungan dengan : tonjolan, tendangan, kelebihan, kepanjangan.

12. Apakah stri larangan merupakan wanita yang dipingit (dlsengker) untuk para bangsawan atau wanita tertentu yang mempunyai kewajiban khusus berkaitan dengan bangunan suci ? Cf. sutrl di Bali, yaitu wanita tua yang bertugas menari sewaktu plodalan pura.

13. Di desa Lasem dekat Sêdayu Kota (Kab. Gresik) masih terdapat sisa bangunan kuna dari bata dan juga penulis pernah menemukan prasasti batu yang sudah dihancurkan berkeping-keping oleh seseorang (mungkin dari masa Airlangga). Dengan demikian tokoh Bhre Lasêm Sang-Alèmu dan Bhre Lasêm Sang-Ayu tidak harus dihubungkan dengan Lasêm di Jawa Tengah. Mungkin yang dimaksud Lasem di dalam kitab Pararaton malahan Lasêm di Kab. Gresik yang lebih dekat dengan Majapahit.

14. Lihat M.M. Sukarto K. Atmodjo : Sedikit tentang nama kota Tuban dan Lamongan, Fak. Sustra Univ. Gadjah Mada, Yogyaka rta, tanggal 24 - 25 Oktober 1980.

15. Lihat M.M. Sukarto K. Atmodjo : Sekitar Masalah Sejarah Kadiri Kuna, diterbitkan oleh Lembaga Javanologi - Universit as Kadiri, 1985.

16. Dukuh Kuwak sekarang terletak di kota Kediri, dan nama pemandian Kuwak sekarang dirubah namanya menjadi pemandian Tirtoyoso. Lihat : Sekitar Masalah Sejarah Kadiri Kuno hIm. 83 - 85.

17. Nama desa Cêkêr sekarang diganti Sukoanyar, terletak kira-kira 10 km. sebelah barat-daya kota Kediri.

18. Di dalam prasasti Bugbug (1103 Saka) yang penulis baca pada tanggal 15 Nopember 1970 dikatakan apabila penduduk desa Bugbug menangkap penyu supaya diserahkan kepada pinisipuh desa, apabila tidak mereka akan dikenakan denda sebesar $4 \mathbf{m a ̄}$ (....... läwan-yan hana wwang-l bugbug sapasukuta amollḥ phùy, wwatakna $\mid$ ri karaman yan-' tan w watakna tibana sipat $m \bar{a} \mathbf{4}$.....). 
19. Krimi oleh Poerbatjaraka diterjemahkan : rupsen (ulat). Kara diterjemahkan : ezels (keledai), sedangkan Pigeaud menterjemahkan kara : tortoises (kura-kura). Demikian pula krimi oleh Pigeaud diterjemahkan : worm (cacing).

20. Papahara oleh Perbatjaraka diterjemahkan; zondig voedsel.

21. Lihat Pigeaud : Javaans - Nederiands Handwoordenboek, J.B. Wolters, Gronigen, Batavia, 1938, hlm. 51. Kalimat itu berarti : tanpa peraturan tanpa undang-undang (pergi).

22. Berarti lebih kurang : "Terucaplah raja Brawijaya keluar di sitinggil, bertanya kepada para nujum, apakah setelah raja meninggal ada seorang raja yang mengganti kedudukannya dan mempunyai kekuasaan seperti beliau. Jawab para nujum. ada, malahan keturunan raja juga . Tetapi akan pindah istana di Mataram, menaklukkan seluruh penduduk di tanah Jawa. Prabu Brawijaya tidak berkata kemudian pulang ke istana. Pada waktu itu sang raja sakit kelamin (rajasinga), dan lama tidak dapat keluar (dihadap hamba). Kemudian pada suatu malam sang raja mendengar suara: "Eh, sang raja, kalau engkau ingin sembuh, supaya bersama-sama tidur orang Wanḑan yang kuning kulitnya". Setelah bangun sang raja kemudian meminta hamba perempuan Wanḍan, yang dibawa oleh istri dari negara Campa. Ketika ditiduri sekali, sang raja sembuh penyakitnya. Hamba perempuan tadi kemudian hamil. melahirkan anak laki-laki, bagus rupanya. Kehendak sang raja, bayi akan diberikan kepada hambanya juru sawah, bernama buyut Masahar. Tetapi setelah berumur satu windu ( 8 tahun), supaya dibunuh, sebab tebakan para nujum, bayi tersebut besuk akan menjadi raja, merusak sang raja Brahwijaya sendiri. Tetapi tebakan para nujum tersebut keliru.

Bayi dibawa pulang oleh Ki Masahar, diserahkan kepada istrinya, supaya dirawat. Setelah puput, diberi nama Raden Bondan Kêjawan. Setelah berumur sewindu. kyai buyut memperingatkan istrinya, apa yang menjadi kehendak sang raja. Lalu menarik keris akan membunuh Raden Bondan Kêjawan. Nyai buyut jatuh pingsan, kyai Masahar gagal (mengurungkan) akan membunuh, cepat menolong istrinya. Karena berat (besar) cintanya kepada istri, Raden Bondan Kêjawan tidak jadi mati. Kyai Masahar kemudian menghadap sang raja berkata berpura-pura, kalau sudah melaksanakan perintahnya. Sangraja sangat senang hatinya". 


\section{DAFTAR PUSTAKA}

Naerssen, F.H. Van. 1941. Oud javaansche Oorkonde in Duitsche en Deensche Verzamelingen disertasi di Rijksuniversiteit Leiden, 1941.

Olthof, W.L. 1941. Poenika Serta Babad Tanah Djawi wiwit saking Nabi Adam doemoegi ing taoen 1647, uitgegeven door Bet Koniklijk Instituut voor de Taal-, Land- en Volkenkunde van Ned. Indie, $M$. Nijhoff, 's Gravenhage.

Pigeaud, Th. 1938. Javaans-Nederlands Handwoordenboek, J. B. Wolters, Gronigen, Batavia, 1938.

Pigeaud, Th. 1960. Java in the Fourteenth Century, Vol. I. Translation Series 4, I - 1960.

Poerbat jaraka, R.Ng. 1933. Nitisastra, Bibliotheca Javanica 4, A.C.NIX \& Co, Bandung.

Stutterheim, W.F. dan Pigeaud, Th. 1926. Een belangrijke Oorkonde uit den Bloeitijd van Madjapahit. Djawa, 1926.

Sukarto K. Atmodjo, M. M. 1980. Sedikit tentang nama kota Tuban dan Lamongan, Fak. Sastra Univ. Gadjah Mada, Yogyakarta, tgl. 24 25 Oktober 1980.

Sukarto K. Atmodjo, 1985. Profil Kodok Dalam Prasasti Kuno, di dalam harian Sinar Harapan, 25 Januari 1985, hlm. VI.

Sukarto K. Atmodjo, 1985. Sekitar Masalah Sejarah Kadiri Kuna (Harijadi Kadiri), diterbitkan oleh Lembaga Javanologi - Universitas Kadiri dengan bantuan Pemerintah Daerah Kabupaten Kediri, 1985. 